\title{
A.М. Сереброва
}

\section{БОРЬБА С "ИСААМСКИМ ГОСУААРСТВОМ": ВОЙНА И ПОАИТИКА}

Аннотация. Анализируются причины, позволившие боевикам «Исламского государства» укрепить свои позиции в странах Ближнего Востока. Подробно рассмотрены иракский и сирийский театры военных действий, а также состояние антитеррористической коалиции. На основании существующих противоречий между участниками борьбы против «Исламского государства» дается прогноз возможных конфликтов в регионе.

Ключевые слова: международный терроризм, исламский радикализм, «Исламское государство», сирийский кризис.

Сереброва Анастасия Михайловна - аспирантка

кафедры глобалистики факультета глобальных процесов

Московского государственного университета им. М.В. Ломоносова.

E-mail: aserebro23@yandex.ru

A.M. Serebrova. The Fight Against the «Islamic State»: The War and Politics

Abstract. The author studies the reasons that allowed the militants of the "Islamic state» to strengthen their positions in the Middle East. The article provides a detailed analysis of the Iraqi and the Syrian theaters of war and the state of anti-terrorist coalition. Basing on the existing contradictions between the fighters against the "Islamic state» the author makes a forecast of the future probable conflicts in the region.

Keywords: international terrorism, Islamic radicalism, Islamic state, the Syrian crisis.

Serebrova Anastasia Mikhailovna - postgraduate student

of the Department of Global studies, the Faculty of Global processes,

Lomonosov Moscow State University. E-mail: aserebro23@yandex.ru.

Среди вызовов, с которыми пришлось столкнуться мировому сообществу в XXI в., одно из первых мест занимает террористическая угроза. Согласно данным Глобального индекса терроризма 2015 (ГИТ), представленного 
Институтом экономики и мира Сиднейского университета [15], за последние 15 лет было совершено свыше 61 тыс. терактов, в результате которых погибли более 140 тыс. человек. При этом количество жертв росло год от года. Если в 2000 г. этот показатель был равен 3329, то в 2014 г. составил 32685 . В 2014 г. количество терактов - по сравнению с 2013 г. - выросло на $61 \%$. Список стран, которым хотя бы раз пришлось столкнуться с терроризмом, пополнили еще восемь. К 2015 г. таких стран стало 67.

Одной из причин подобного «осложнения болезни» является активизация деятельности исламских радикальных движений и группировок. Бациллы исламского радикализма уже поразили Америку, Африку, Азию, а также страны Европейского союза, где с января 2015 по июль 2016 г. погибли не менее 306 человек и около 1 тыс. получили ранения [8]. Тем не менее главным очагом этой «инфекции» по-прежнему остается Ближний Восток. Ирак, Афганистан, Пакистан, Сирия - именно на эти страны приходится $57 \%$ терактов и 78\% погибших в 2014 г. Главным носителем и распространителем угрозы в регионе и за его пределами выступает запрещенная в России группировка «Исламское государство» (ИГ), также известная как ИГИЛ или ДАИШ. В 2013 г. ИГИЛ взяло на себя ответственность за 77\% произошедших в мире террористических актов, а в 2014 г. уже 95\% случаев атак террористов были делом рук этой организации. Эффективных методов борьбы, с помощью которых можно было бы окончательно уничтожить этот источник террора, пока не нашли.

Феномену «Исламского государства» посвящена не одна статья как в научной литературе, так и в научно-популярных изданиях. 29 июня 2014 г. (в первую ночь Священного месяца Рамадан) Абу Бакр аль-Багдади, лидер исламистской террористической организации «Исламское государство», заявил о намерении создать Всемирный халифат. 5 июля в иракской мечети в Мосуле аль-Багдади нарек себя халифом [5]. Создав государствоподобное образование, радикальные исламисты продемонстрировали немалые геополитические амбиции.

По упоминанию в СМИ ИГИЛ вскоре обошло и «Аль-Каиду», бывшую некогда «террористической организацией № 1» в мире, и «Джабхат анНусру», пик медийной популярности которой пришелся на 2013 г. [9]. На наш взгляд, существует несколько факторов, способствовавших трансформации ИГИЛ из заурядной террористической группировки в главный источник террористической угрозы.

Организационно-управленческие ресурсы. Один из факторов такой трансформации - разветвленная и гибкая внутренняя структура ИГИЛ, структура, способная восстанавливаться даже в критических условиях. Так, например, после ликвидации в 2010 г. полевого командира Абу Айюба альМасри, а затем в феврале 2011 г. его преемника Ан-Насера Лидинилла Абу 130 
Сулеймана организация не пришла в упадок. У ИГИЛ выверенная иерархичная система «государственной службы», включающая двух заместителей (амиров) халифа, 12 губернаторов (вали), которые отвечают за подконтрольные территории в Ираке и Сирии, и кабинет министров. Поэтому смерть главаря не ведет к прекращению активности группировки.

Важной характеристикой управленческого ресурса является его качественный состав. В рядах джихадистов ИГИЛ немало профессиональных военных. В том числе кадровые офицеры и сотрудники спецслужб бвшей армии Саддама Хусейна.

Материально-финансовые ресурсы. Второй фактор устойчивости ИГИЛ - наличие значительных материальных ресурсов. По данным исследовательского центра HIS Markit, в месяц доход ИГИЛ составляет 80 млн долл. [17], а в декабре 2015 г. бюджет группировки был равен 2 млрд долл. [18]. Наличие подобных крупных финансовых потоков отличает «Исламское государство» от других террористических группировок исламистского толка. Для сравнения на рис. 1. представлены бюджеты наиболее «медийных» террористических групп.

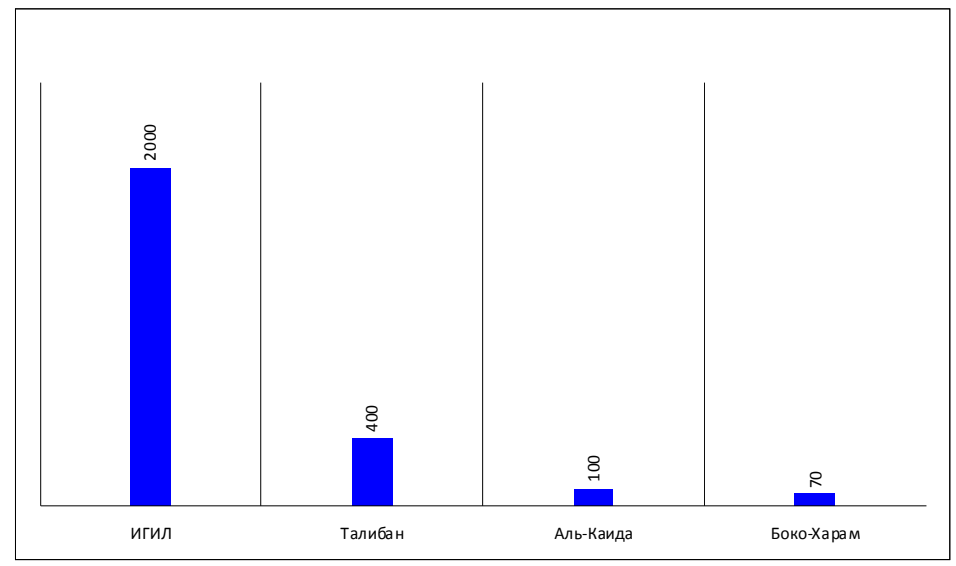

Рис. 1. Бюджет исламистских террористических группировок

В 2014 г., МАн АОАл.

Источник: Составлена автором по материалам программы «Вести. Экономика» от 23.06.2014 [12]. 


\section{РОССИЯ И МИР В ХХІ ВЕКЕ}

Российские и международные эксперты выделяют различные источники финансирования «Исламского государства». Достаточно широкий перечень такого рода источников приводит Е.С. Бирюков [2, с. 6-30]. Он выделяет в качестве основных наркоторговлю, рэкет, конфискации, торговлю людьми, артефактами и сырьем, офшорные инвестиции, деятельность исламских банков, дотации из средств благотворительных фондов и спонсорство отдельных лиц. Последний пункт также нашел отражение в докладе, представленном Кристин Духайме [16, с. 3], специалистом по противодействию коррупции и финансированию терроризма. Как отмечает Духайме, «согласно данным Министерства финансов США, первичным источником финансирования “Исламского государства” выступают индивидуальные собственники и организации из Катара и Кувейта».

А.В. Федорченко и А.В. Крылов, описывая финансово-экономическую систему ИГИЛ, называют пять основных источников получения прибыли: традиционные исламские системы налогов и денежных переводов, законная финансовая деятельность, нелегальный теневой бизнес и экспроприация [10].

Мы предлагаем систематизировать вышеперечисленные источники, взяв за основу классификации два критерия: локация получения дохода и правомерность источника финансирования. Объединение этих критериев позволяет выделить четыре группы (см. табл. 1).

ИСТОЧНИКИ ПОАУЧЕНИЯ АОХОАА

Таблица 1 "ИСААМСКИМ ГОСУААРСТВОМ"

\begin{tabular}{|c|c|}
\hline $\begin{array}{l}\text { 1. Легальные внутренние } \\
\text { - закят (регулярные обязательные отчисле- } \\
\text { ния верующих в рамках исламской системы } \\
\text { налогообложения) } \\
\text { - садака (добровольные жертвования ве- } \\
\text { рующих на благотворительные нужды) }\end{array}$ & $\begin{array}{l}\text { 2. Легальные внешние } \\
\text { - хаваля (мусульманская система денежных } \\
\text { переводов исламскими банками) }\end{array}$ \\
\hline $\begin{array}{l}\text { 3. Нелегальные внутренние } \\
\text { - экспроприация (отчуждение собственности } \\
\text { путем захвата или принудительной сдачи) }\end{array}$ & $\begin{array}{l}\text { 4. Нелегальные внешние } \\
\text { - теневой бизнес (наркоторговля, продажа } \\
\text { нефти) }\end{array}$ \\
\hline
\end{tabular}

Источник: Составлено автором по опубликованным материалам $[2 ; 16 ; 10]$.

Информационные ресурсы. Наконец, третий фактор устойчивости ИГИЛ - эффективная пропагандистская деятельность, в результате которой ряды боевиков неустанно пополняются молодежью. Пропаганда неосуществима без двух основных компонентов: идеологии и технологии. ИГИЛ обладает обоими этими компонентами. 
Идеология «Исламского государства» представляет собой набор тезисов салафитского толка, в которых предлагается исламский вариант социального возрождения в условиях системного социально-политического, экономического и идеологического кризисов. Исследователи Д.И. Моторин и В.Д. Коваленко отмечают, что, несмотря на идеалистическую направленность, идеологии ИГИЛ - «ввиду практической ориентированности на обнищавшие в результате войн слои населения» - присущ консолидирующий потенциал [7].

Современные технологии (средства обработки и передачи информации) выступают главным инструментом распространения идеологии. Первостепенную роль в этом играют социальные сети. Как отметил Муваффака альРубаи, бывший член иракского Управляющего совета, занимавший с 2004 по 2009 г. должность советника по национальной безопасности Ирака, «благодаря твиттеру и фейсбуку 30 тыс. солдат иракских сил безопасности бросили оружие, сняли с себя военную форму и без боя оставили Мосул» [6].

Таким образом, борьба с ИГИЛ представляет собой сложный многоаспектный процесс, состоящий из нескольких взаимосвязанных аспектов: социально-идеологического, экономического и военно-политического, который будет наиболее подробно рассмотрен в данной статье.

Если до 2013 г. группировка насчитывала около 4 тыс. человек, то по данным журнала «Economist», опубликованным в июне 2014 г., на стороне ИГИЛ воевали не менее 11 тыс. человек [19]. Из них от 3 до 5 тыс. находятся в Сирии и 6 тыс. - в Ираке. Таким образом, именно эти две страны выступают основными театрами военных действий.

Ирак. Ирак можно назвать «малой родиной» ИГИЛ, поскольку именно с этой страной связан период становления организации. После свержения режима Саддама Хусейна в 2003 г. радикальные исламисты получили возможность беспрепятственного проникновения на территорию Ирака. В 2006 г. семь разрозненных группировок суннитского толка объединились в «Совещательное собрание моджахедов» (другое название «Совет моджахедов шуры»), а после того, как к ним примкнули еще четыре организации, 15 октября 2006 г. было объявлено о создании «Исламского государства Ирака» (ИГИ), впоследствии пополнявшегося рядом мелких группировок. ИГИ выступало за очищение ислама и освобождение Ирака от западной антитеррористической коалиции. В 2013 г. название группировки поменялось на «Исламское государство в Ираке и Шаме» (термин Левант является латинизированным аналогом арабского понятия аш-Шам, под которым подразумевается регион, объединяющий территорию Ливана, Сирии, Палестины и части Иордании), что подчеркивало планы дальнейшей экспансии террористов. 


\section{РОССИЯ И МИР В ХХІ ВЕКЕ}

Мировое сообщество стало воспринимать организацию всерьез, когда летом 2014 г. ИГИЛ начала наступление на север Ирака, а к осени того же года контролировала уже около $45 \%$ территории страны. За несколько месяцев были взяты крупные города, в числе которых Мосул (третий по величине город-миллионер в Ираке, административный центр провинции Найнава) и Киркук (центр одноименной провинции, богатой нефтеносными месторождениями). Меньше чем за год группировка исламистов распространила свое влияние в «суннитском треугольнике», состоящем из шести провинций. Условные «вершины» этого «треугольника» на севере Ирака в Эр-Рамади, Тикрите и в центральной части страны в Багдаде.

Можно выделить несколько причин, объясняющих достижение столь масштабных военных успехов за короткий промежуток времени.

Умелое использование внутрирелигиозных противоречий. В Ираке ставка была сделана на недовольство части суннитских племен, проживающих на севере. Они были недовольны тем, что руководящие посты в стране сконцентрированы в руках шиитов, ущемляющих их права. Главными сторонниками ИГИЛ в Ираке являются «баасисты», т.е. выходцы из партии «Баас», которая лишилась статуса «правящей» и была запрещена после свержения Саддама Хусейна. Дебаасификация затронула в первую очередь офицеров-суннитов бывшей саддамовской армии, не допускавшихся к службе в новых вооруженных силах. В то же время в поддержке со стороны «баасистов» оказалось заинтересованным руководство ИГИ. Оно начало активно привлекать на свою сторону представителей бывшей иракской военной элиты, выдвигая их на «ключевые посты в Военном совете группировки» [4, с. 29-30]. Это способствовало реорганизации ИГИ и созданию внутри нее полноценных боеспособных армейских структур. Так, в январе 2014 г. «баасистами» был основан «Главный военный совет иракских революционеров», силы которого сыграли решающую роль при захвате городов Фалуджа и Рамади.

Стратегически верно выбранное направление удара. Как уже было отмечено выше, «Исламское государство» распространило свое влияние в пределах «суннитского треугольника», т.е. той части территории Ирака, где преобладающим является суннитское население. Выбор этого района был обоснован не только его конфессиональной характеристикой, но и важным стратегическим значением «вершин треугольника». Тикрит, центр провинции Салах-эд-Дин, является малой родиной Саддама Хусейна. Костяк Вооруженных сил составляют бывшие «саддамовцы» - а значит, взятие города было символом, вдохновившим террористов на дальнейшие победы. Не менее важным является контроль над провинцией Анбар, центр которой расположен в городе Эр-Рамади. Как отмечает сотрудник Института Ближнего Востока Ю.Б. Щегловин, эта территория «является своеобразной "реперной точкой”» [11]. Поскольку через Анбар проходит 90\% логистических коридоров 
материально-технического снабжения, контроль над провинцией означает не только фактическое кураторство над всем «суннитским треугольником», но и единство ирако-сирийского фронта.

Непрерывное пополнение ресурсов, или «эффект снежного кома». Первые два пункта можно рассматривать как причины первоначальных успехов ИГИЛ в военной сфере. Вместе с тем они оказали косвенное воздействие на запуск «эффекта снежного кома»: ресурсы, переходившие в руки исламистов после обретения контроля над иракскими территориями, формировали прочную материальную базу для дальнейшего продвижения в глубь страны. Взятие Мосула, например, означало получение контроля над нефтяными месторождениями и, следовательно, расширение структуры теневого бизнеса. Кроме того, как отмечает Б.В. Долгов, боевикам удалось захватить большое количество вооружения американского производства, брошенного Иракской армией в ходе отступления. Стоит также учесть человеческий ресурс, непрерывно пополняющийся как за счет добровольцев, так и за счет пленных. В итоге «Исламское государство» смогло позволить себе ведение боевых действий не только на Иракском, но и на Сирийском фронтах.

Сирия. Уже более пяти лет события в Сирии формируют современную военно-политическую повестку дня. Вспыхнувшие в 2011 г. антиправительственные волнения достаточно быстро разрослись до полномасштабной гражданской войны, а с вмешательством сил международной коалиции и активизацией террористических структур этот клубок противоречий стал еще более запутанным.

Можно выделить четыре «пласта» конфликта (рис. 2)

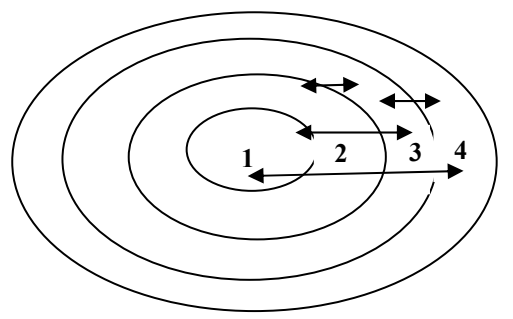

1 - антиправительственные волнения

2 - курдский вопрос

3 - террористическая угроза

4 - международная коалиция

$\longrightarrow$ направления противодействия

Рис. 2. "Пласты" конфяикта в Сирии

Источник: Составлено автором.

Как видно из рис. 2, после вторжения на территорию Сирии в 2014 г. боевики «Исламского государства» ведут боевые действия одновременно на трех направлениях: во-первых, ИГИЛ, поддерживая оппозицию, противостоит 
законному правительству страны во главе с Башаром Асадом; во-вторых, мощное сопротивление исламистам оказывают сирийские курды, и наконец с терроризмом борется международная коалиция. В то же время за 20142015 гг. исламисты смогли достичь значительных результатов: совместно с антиправтельствами силами ИГИЛ контролировало $80 \%$ территории страны, в том числе город Ракка, выбранный столицей непризнанного государства.

Успешность «Исламского государства» в Сирии имела под собой следующие основания.

Поддержка суннитского населения. Распределение власти с учетом этнорелигиозных признаков является одной из причин гражданской войны в Сирии. Как и в Ираке, боевики «Исламского государства» опирались на суннитское население страны. Захваченные районы отдаленной провинции Ракка были населены преимущественно мусульманами-суннитами и не оказывали должного сопротивления.

Бездействие международной коалиции. В период распространения ИГИЛ на территории Сирии ведущие страны НАТО во главе с США не предпринимали активных действий, чтобы противостоять этому наступлению. Напротив, международная коалиция оказывала поддержку всем оппозиционным силам, выступавшим за свержение сирийского президента Башара Асада.

С 2014 по 2015 г. коалиция во главе с США смогла освободить лишь около $1 \%$ контролируемой «Исламским государством» территории, а 170 нанесенных американскими ВВС авиаударов по позициям исламистов на севере Ирака поразили менее 100 боевиков [3, с. 27]. До вмешательства России в конфликт результаты борьбы с ИГИЛ были весьма скромными.

По оценкам специалистов, территория, контролируемая ИГИЛ, уменьшается. По данным HIS Markit [20], в январе 2015 г. «Исламское государство» оккупировало $90800 \mathrm{kм}^{2}$. За год этот показатель снизился на $15 \%$, составив

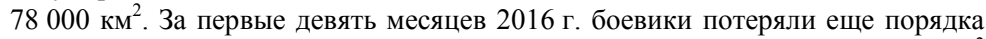
$14 \%$ занимаемой территории, всё же сохранив за собой около 65500 км $^{2}$ в Ираке и Сирии (площадь, сопоставимая с территорией Шри-Ланки). Эти потери во многом стали результатом активизация деятельности международной коалиции, но в первую очередь Российской Федерации, помогающей Иракской и Сирийской армиям в борьбе с терроризмом.

Помимо международной коалиции, задействованной на обоих фронтах, в соответствии с театрами военных действий выделяются еще две основные группы противодействующих «Исламскому государству» сил (см. табл. 2). 
ПРОТИВНИКИ “ИСААМСКОГО ГОСУААРСТВА"

\begin{tabular}{|c|c|c|}
\hline Противники ИГ в Ираке & Противники ИГ в Сирии & Международная коаличия \\
\hline $\begin{array}{l}\text { - Иракская армия «амери- } \\
\text { канского образца» } \\
\text { - Иракская армия «иран- } \\
\text { ского образца» (шиитская } \\
\text { милиция) } \\
\text { - «Пешмерга» } \\
\text { женные силы Иоору- } \\
\text { Курдистана) }\end{array}$ & $\begin{array}{l}\text { - Сирийские вооруженные } \\
\text { силы во главе с Б. Асадом } \\
\text { • Силы народной само- } \\
\text { обороны } \\
\text { • «Хезболла» (ливанская } \\
\text { шиитская группировка) } \\
\text { - Партия Демократическо- } \\
\text { го единства (сирийские кур- } \\
\text { ды) }\end{array}$ & $\begin{array}{l}\text { - Россия } \\
\text { - США + страны - союз- } \\
\text { ники Персидского залива } \\
\text { (Саудовская Аравия, Катар, } \\
\text { ОАЭ, Бахрейн, Иордания) } \\
\text { - Иран («Корпус стражей } \\
\text { исламской революции» и } \\
\text { добровольцы) }\end{array}$ \\
\hline
\end{tabular}

Источник: Составлена автором.

Как видно из таблицы 2, ИГИЛ противостоит достаточно мощный блок, включающий две ядерные державы и военные силы локального значения. Однако, несмотря на достигнутые успехи, коалиция продвигается по территориям, оккупированным ИГИЛ, медленно. Сложившаяся ситуация объясняется не только мощью противника, но и политическими противоречиями внутри блока. Рассмотрим несколько конфликтных осей.

США - Ирак - Иран. Соединенные Штаты Америки являются одним из ключевых игроков на Ближнем Востоке. Стратегия их деятельности базируется на идее глобального лидерства. Эта стратегия продиктована прагматичным подходом к анализу политической ситуации в регионе.

Действия США в отношении Ирака стали одной из причин, спровоцировавшей затянувшийся иракский кризис. После вторжения в Ирак в 2003 г. и свержения Саддама Хусейна США способствовали приходу во власть Нури ал-Малики, представителя шиитской общины. После того как новый премьер-министр решает проводить политику сближения с Ираном, претендентом на лидерство в регионе, США сделали ставку на оппозиционные силы, наиболее боеспособными из которых стало «Исламское государство».

Примечательно, что в 2014 г., в период расцвета ИГИЛ, в Ираке спровоцирован новый правительственный кризис: в результате давления оппозиции и США вынужден уйти в отставку Нури ал-Малики. Временное ослабление центральной власти в стране позволило боевикам «Исламского государства» получить дополнительное время для наращивания боеспособности.

США и западная коалиция - Свободная армия Сирии - Сирийское правительство - страны Персидского залива - Иран - Россия. В Сирии террористическая угроза является лишь одним из пластов общей конфликтогенной зоны. На рисунке 2 показано, что силы международной коалиции задействованы не только в борьбе с «Исламским государством», но и в разрешении внутрисирийского конфликта. В данном процессе обнаруживаются 
сразу несколько сторон, соперничающих за влияние в регионе: США vs Pocсия, Саудовская Аравия vs Иран.

С момента перерастания народных волнений в гражданскую войну Запад выступает на стороне сирийской оппозиции. Такой же позиции придерживаются нефтедобывающие страны Персидского залива (Саудовская Аравия, Кувейт, Катар), предложившие оппозиционной Асаду «Свободной сирийской армии» создать тренировочную базу на своей территории. Единодушие в данном вопросе неслучайно. Дестабилизация обстановки в Сирии является важным фактором сдерживания амбиций Ирана.

Для России укрепление позиций в Средиземном море является важной стратегической задачей, а единственная военная база, позволяющая это сделать, расположена в Тартусе. Смена дружественного нашей стране режима вряд ли позволила бы России сохранить позиции в этом регионе. В то же время для России в Сирии главным является нивелирование террористической угрозы.

Приход к власти исламистов, выступающих на стороне оппозиции, может нанести значительный урон национальной безопасности России. Как отмечает директор Центра изучения стран Ближнего Востока и Центральной Азии С.А. Багдасаров, «значительная часть тех, кто воюет там - узбеки, таджики и так далее, - были завербованы среди гастарбайтеров, которые работали на территории России» [1, с. 134]. Даже если представители перечисленных национальностей вернутся не в Россию, а на родину, потенциальная угроза для нашей страны по-прежнему будет сохраняться. Возвращение этих людей в бывшие центральноазиатские советские республики, по-прежнему тесно связанные с Россией, вполне может создать в этих республиках ситуацию хаоса. Кроме того, радикально настроенные молодые люди могут вернуться и в Россию - в поисках работы.

США и западная коалиция - Ирак - Иракский Курдистан - Турция. Наиболее боеспособной силой в Ираке является курдское вооруженное формирование «Пешмерга», бойцы которого сдерживают «Исламское государство» на линии фронта в провинции Киркур. Иракским курдам западная коалиция во главе с США оказывает активную поддержку, поставляя военное снаряжение и гуманитарную помощь, проводя совместные учения. В частности, с сентября 2014 г. Германия направила «Пешмерге» более 2 тыс. т оружия на сумму 90 млн евро. В настоящий момент около 150 немецких военнослужащих базируются в Эрбиле, столице Иракского Курдистана, и решением бундесвера тренировочная миссия будет продлена до 2018 г. [13].

На фоне усиления связей с западной коалицией всё более напряженными становятся отношения Иракского Курдистана с Ираком. В результате краха режима Саддама Хусейна курды получили значительную автономию и намерены провести референдум о независимости. Безусловно, официальный 
Багдад выступает против подобных стремлений, но периодически возникающие столкновения (как, например, в 2016 г. между курдскими силами и шиитскими ополченцами) лишь накаляют обстановку. В феврале 2017 г. во время встречи с немецкой делегацией премьер-министр Регионального правительства Курдистана (КРГ) Нечирван Барзани заявил, что «кроме военной координации между КРГ и иракским федеральным правительством в текущей операции в Мосуле, в связях между ними не произошло никаких других улучшений» [14].

В независимости Иракского Курдистана заинтересованы США и страны $\mathrm{EC}$, поскольку с отделением Эрбиля (столицы Иракского Курдистана) от Багдада они получают возможность, во-первых, еще больше ослабить Ирак, а во-вторых, создать в регионе лояльное своей политике государство. Есть вероятность, что данный шаг спровоцирует «эффект домино»: вслед за иракскими курдами о своей независимости могут заявить сирийские и турецкие курды. Последние составляют значительную общину в Турции. При этом власти Турции придерживаются политики неоосманизма и единства страны, ведут борьбу с Рабочей партией Курдистана. Соответственно, вполне вероятно, что курдский вопрос может стать «яблоком раздора» между Турцией и ее союзниками по НАТО.

Таким образом, в борьбе с «Исламским государством» участники коалиции руководствуются в первую очередь собственными политическими интересами в регионе. Подобный подход значительно уменьшает эффективность совершаемых действий. Кроме того, даже в случае победы над главным источником террористической угрозы велика вероятность возникновения конфликтов между участниками коалиции. А это, в свою очередь, создает благоприятные условия для возрождения и усиления ИГ. Поэтому важной составляющей борьбы с «Исламским государством» является выработка четкой стратегии послевоенного устройства в регионе, главным образом в Ираке и Сирии, а также решение курдского вопроса.

\section{Библиография}

1. Багдасаров С.А. Ближний Восток: Вечный конфликт. М.: Издательство «Э», 2016. $288 \mathrm{c}$.

2. Бирюков Е.С. Финансовые пружины международного терроризма и его угроза безопасности терроризма. Ключевые источники финансирования терроризма. Часть 1 // Обозреватель - Observer. 2016. № 1 (312). С. 6-30.

3. Долгов Б.В. «Исламское государство»: Причины возникновения и перспективы // Арабский кризис: Угрозы большой войны / Под общей ред. А.М. Васильева; отв. ред. А.Д. Саватеев, А.Р. Шишкина. М.: ЛЕНАНД, 2016. С. 16-29.

4. Тарасевич Е.А. Исламское возрождение иракской партии «Баас» // Арабский кризис: Угрозы большой войны / Под общей ред. А.М. Васильева; отв. ред. А.Д. Саватеев, А.Р. Шишкина. М.: ЛЕНАНД, 2016. 


\section{РОССИЯ И МИР В ХХІ ВЕКЕ}

5. Куприянов А. Возвращение халифа. Как «Аль-Каида» случайно восстановила Исламский халифат и что из этого вышло // Lenta.ru. 2014. URL: https://enta.ru/articles/2014/09/11/isis/ (Дата обращения: 29.09.2016.)

6. Майкл Вайсс, Хасан Хасан. Обаяние жестокости и радикализма // Россия в глобальной политике. 2015. № 5. URL: http://globalaffairs.ru/number/Obayanie-zhestokosti-i-radikalizma17740 (Дата обращения: 29.01.2017.)

7. Моторин Д.И., Коваленко В.Д. Специфика информационной борьбы запрещенных в России террористических организаций «Аль-Каида» и ИГИЛ // Научный журнал «Общество: Политика, экономика, право». 2016. № 5. URL: http://dom-hors.ru/rus/files/arhiv_zhurnala/ pep/ 2016/5/politics/motorin-kovalenko.pdf (Дата обращения: 29.01.2017.)

8. Сидорчик А. Это - война. Пять крупнейших терактов в Европе в 2015-2016 гг. // Аргументы и факты. 2016. URL: http://www.aif.ru/society/safety/eto_-_voyna_pyat_krupneyshih_ teraktov_evrope_v_2015-2016_godah (Дата обращения: 24.08.2016.)

9. Столповский О. Феномен «Исламского государства», или Очередной Франкенштейн на мировой арене. Интервью с экспертом по вопросам Ближнего Востока Арминэ Акопяном // Интернет-портала Antiterrortoday.com. 2014. URL: http://antiterrortoday.com/ru/eksklyuziv/5856fenomen-islamskogo-gosudarstva-ili-ocherednoj-frankenshtejn-na-mirovoj-arene (Дата обращения: 24.08.2016.)

10. Федорченко А.В., Крылов А.В. Феномен «Исламского государства» // Вестник МГИМО. 2015. № 2 (41). URL: http://cyberleninka.ru/article/n/fenomen-islamskogo-gosudarstva (Дата обращения: 29.01.2017.)

11. Щегловин Ю.Б. Ирак: О ситуации в провинции Анбар // Институт Ближнего Востока. 2015. URL: http://www.iimes.ru/?p=24351 (Дата обращения: 15.02.2017.)

12. 7 самых богатых террористических группировок в мире // Вести. Экономика. Эфир от 23.06.2014. URL: http://www.vestifinance.ru/articles/44210 (Дата обращения: 12.11.2016.)

13. Германия продолжит военное обучение Пешмерга в 2017 г. // RIATAZA. 2017. URL: http://riataza.com/2017/01/13/germaniya-prodolzhit-voennoe-obuchenie-peshmerga-v-2017-godu/ (Дата обращения: 15.02.2017.)

14. Премьер-министр Курдистана провел совещание с немецкой делегацией // KURDISTAN.RU. 2017. URL: http://kurdistan.ru/2017/02/03/news-28477_Premer-ministr_Kurdistana_provel_soveschanie_s_nemeckoy_delegaciey.html (Дата обращения: 15.02.2017.)

15. Global Terrorism Index 2015: Measuring and understanding the impact of terrorism // Institute for Economics and Peace, 2015. URL: http://economicsandpeace.org/wp-content/uploads/2015/ 11/2015-Global-Terrorism-Index-Report.pdf (Дата обращения: 24.08.2016.)

16. Christine Duhaime. Terrorist Financing and the Islamic State // Duhaime Law. 2015. P. 3. URL: http://www.duhaimelaw.com/wp-content/uploads/2015/04/White-Paper-Terrorist-FinancingMethods1.pdf (Дата обращения: 24.08.2016.)

17. Lianna Brinded. The ISIS economy pulls in $\$ 80$ million A MONTH in revenue for the terror group // Business Insider. 2015. URL: http://www.businessinsider.com/how-much-and-how-isismakes-money-2015-12 (Дата обращения: 07.11.2016.)

18. Richard Spencer. How Isil make their money // Financial Times. 2015. URL: http://www. telegraph.co.uk/news/2016/03/18/how-isil-make-their-money/ (Дата обращения: 12.11.2016.)

19. Two Arab countries fall apart// The Economist. 2014. URL: http://www.economist.com/ news/middle-east-and-africa/21604230-extreme-islamist-group-seeks-create-caliphate-and-spreadjihad-across (Дата обращения: 12.11.2016.)

20. Islamic State Caliphate Shrinks by 16 Percent in 2016 // IHS Markit, 2016. URL: http:// news.ihsmarkit.com/press-release/aerospace-defense-security/islamic-state-caliphate-shrinks-16percent-2016-ihs-markit- (Дата обращения: 15.02.2017.) 


\section{References}

Bagdasarov S.A. Blizhnij Vostok: Vechnyj konflikt. Moscow: Izdatel'stvo «Je», 2016. 288 p.

Birjukov E.S. Finansovye pruzhiny mezhdunarodnogo terrorizma i ego ugroza bezopasnosti terrorizma. Kljuchevye istochniki finansirovanija terrorizma. Chast' 1 // Obozrevatel' - Observer. 2016. N 1 (312). P. 6-30.

Dolgov B.V. «Islamskoe gosudarstvo»: Prichiny vozniknovenija i perspektivy // Arabskij krizis: Ugrozy bol'shoj vojny / Pod obshhej red. A.M. Vasil'eva; otv. red. A.D. Savateev, A.R. Shishkina. Moscow: LENAND, 2016. P. 16-29.

Tarasevich E.A. Islamskoe vozrozhdenie irakskoj partii «Baas» // Arabskij krizis: Ugrozy bol'shoj vojny / Pod obshhej red. A.M. Vasil'eva; otv. red. A.D. Savateev, A.R. Shishkina. Moscow: LENAND, 2016. P. 30-29.

Kuprijanov A. Vozvrashhenie halifa. Kak «Al'-Kaida» sluchajno vosstanovila Islamskij halifat i chto iz jetogo vyshlo // Lenta.ru. 2014. URL: https://lenta.ru/articles/2014/09/11/isis/ (Data obrashhenija: 29.09 .2016$.

Majkl Vajss, Hasan Hasan. Obajanie zhestokosti i radikalizma // Rossija v global'noj politike. 2015. N 5. URL: http:/globalaffairs.ru/number/Obayanie-zhestokosti-i-radikalizma-17740 (Data obrashhenija: 29.01.2017.)

Motorin D.I., Kovalenko V.D. Specifika informacionnoj bor'by zapreshhjonnyh v Rossii terroristicheskih organizacij «Al'-Kaida» i IGIL // Nauchnyj zhurnal «Obshhestvo: Politika, jekonomika, pravo». 2016. N 5. URL: http://dom-hors.ru/rus/files/arhiv_zhurnala/pep/2016/5/politics/ motorin-kovalenko.pdf (Data obrashhenija: 29.01.2017.)

Sidorchik A. Jeto - vojna. Pjat' krupnejshih teraktov v Evrope v 2015-2016 godah // Argumenty i fakty. 2016. URL: http://www.aif.ru/society/safety/eto_-_voyna_pyat_krupneyshih_teraktov_ evrope_v_2015-2016_godah (Data obrashhenija: 24.08.2016.)

Stolpovskij O. Fenomen «Islamskogo gosudarstva», ili ocherednoj Frankenshtejn na mirovoj arene. Interv'ju s jekspertom po voprosam Blizhnego Vostoka Arminje Akopjanom // Internet-portala Antiterrortoday.com. 2014. URL: http://antiterrortoday.com/ru/eksklyuziv/5856fenomen-islamskogo-gosudarstva-ili-ocherednoj-frankenshtejn-na-mirovoj-arene (Data obrashhenija: 24.08.2016.)

Fedorchenko A.V., Krylov A.V. Fenomen «Islamskogo gosudarstva»// Vestnik MGIMO. 2015. N 2 (41). URL: http://cyberleninka.ru/article/n/fenomen-islamskogo-gosudarstva (Data obrashhenija: 29.01.2017.)

Shheglovin Ju.B. Irak: O situacii v provincii Anbar // Institut Blizhnego Vostoka. 2015. URL: http://www.iimes.ru/?p=24351 (Data obrashhenija: 15.02.2017.)

7 samyh bogatyh terroristicheskih gruppirovok v mire // Vesti. Jekonomika. Efir ot 23.06.2014. URL: http://www.vestifinance.ru/articles/44210 (Data obrashhenija: 12.11.2016.)

Germanija prodolzhit voennoe obuchenie Peshmerga v 2017 godu // RIATAZA. 2017. URL: http://riataza.com/2017/01/13/germaniya-prodolzhit-voennoe-obuchenie-peshmerga-v-2017-godu/ (Data obrashhenija: 15.02.2017.)

Prem'er-ministr Kurdistana provel soveshhanie s nemeckoj delegaciej // KURDISTAN.RU. 2017. URL: http://kurdistan.ru/2017/02/03/news-28477_Premer-ministr_Kurdistana_provel_soveschanie_s_nemeckoy_delegaciey.html (Data obrashhenija: 15.02.2017.)

Global Terrorism Index 2015: Measuring and understanding the impact of terrorism // Institute for Economics and Peace, 2015. URL: http://economicsandpeace.org/wp-content/uploads/2015/11/2015-Global-Terrorism-Index-Report.pdf (Data obrashhenija: 24.08.2016.)

Christine Duhaime. Terrorist Financing and the Islamic State // Duhaime Law. 2015. P. 3. URL: http://www.duhaimelaw.com/wp-content/uploads/2015/04/White-Paper-Terrorist-FinancingMethods1.pdf (Data obrashhenija: 24.08.2016.) 


\section{РОССИЯ И МИР В ХХІ ВЕКЕ}

Lianna Brinded. The ISIS economy pulls in $\$ 80$ million A MONTH in revenue for the terror group // Business Insider. 2015. URL: http://www.businessinsider.com/how-much-and-how-isismakes-money-2015-12 (Data obrashhenija: 07.11.2016.)

Richard Spencer. How Isil make their money // Financial Times. 2015. URL: http://www.telegraph.co.uk/news/2016/03/18/how-isil-make-their-money/ (Data obrashhenija: 12.11.2016.)

Two Arab countries fall apart // The Economist. 2014. URL: http://www.economist.com/ news/middle-east-and-africa/21604230-extreme-islamist-group-seeks-create-caliphate-and-spreadjihad-across (Data obrashhenija: 12.11.2016.)

Islamic State Caliphate Shrinks by 16 Percent in 2016 // IHS Markit, 2016. URL: http://news.ihsmarkit.com/press-release/aerospace-defense-security/islamic-state-caliphate-shrinks16-percent-2016-ihs-markit (Data obrashhenija: 15.02.2017.) 